\title{
CHARACTERIZATION OF LAND COVER SEASONALITY IN SENTINEL-1 TIME SERIES DATA
}

\author{
C. Dubois ${ }^{1, *}$, M. M. Mueller ${ }^{1}$, C. Pathe ${ }^{1,2}$, T. Jagdhuber ${ }^{3}$, F. Cremer ${ }^{1,2}$, C. Thiel ${ }^{2}$, C. Schmullius ${ }^{1}$ \\ ${ }^{1}$ Department for Earth Observation, Institute of Geography, Friedrich-Schiller University, Jena, Germany - (clemence.dubois, \\ marlin.markus.mueller, carsten.pathe, felix.cremer, c.schmullius)@uni-jena.de \\ ${ }^{2}$ Institute of Data Science, German Aerospace Center, Jena, Germany - (carsten.pathe, felix.cremer, Christian.Thiel)@dlr.de \\ ${ }^{3}$ Microwaves and Radar Institute, German Aerospace Center, Wessling, Germany - thomas.jagdhuber@dlr.de
}

\section{Commission III, WG III/2}

KEY WORDS: Sentinel-1, C-band, time series, multi-temporal, phenology, vegetation, soil

\begin{abstract}
:
In this study, we analyze Sentinel-1 time series data to characterize the observed seasonality of different land cover classes in eastern Thuringia, Germany and to identify multi-temporal metrics for their classification. We assess the influence of different polarizations and different pass directions on the multi-temporal backscatter profile. The novelty of this approach is the determination of phenological parameters, based on a tool that has been originally developed for optical imagery. Furthermore, several additional multitemporal metrics are determined for the different classes, in order to investigate their separability for potential multi-temporal classification schemes. The results of the study show a seasonality for vegetation classes, which differs depending on the considered class: whereas pastures and broad-leaved forests show a decrease of the backscatter in VH polarization during summer, an increase of the backscatter in VH polarization is observed for coniferous forest. The observed seasonality is discussed together with meteorological information (precipitation and air temperature). Furthermore, a dependence of the backscatter of the pass direction (ascending /descending) is observed particularly for the urban land cover classes. Multi-temporal metrics indicate a good separability of principal land cover classes such as urban, agricultural and forested areas, but further investigation and use of seasonal parameters is needed for a distinct separation of specific forest sub-classes such as coniferous and deciduous.
\end{abstract}

\section{INTRODUCTION AND STATE-OF-THE-ART}

Due to their weather and daylight independence, SAR satellites are optimal instruments for regular monitoring of the Earth's surface. In the past, SAR satellite data were either only commercially available or showed repeat cycles of more than a month, limiting their use for seasonality analysis. The launch of Sentinel 1A in April 2014 opened the path to free and openly available SAR data worldwide with a nominal repeat cycle of 12 days, allowing the monitoring of short-term changes. The launch of its twin-satellite Sentinel-1B in April 2016 further shortened the revisit time to a nominal 6 days repeat pattern over Europe. This new era of data availability opens the floor for precise multitemporal analysis of the Earth's surface and for the improvement of approaches such as new speckle filters (Cremer et al., 2018) previously limited by the number of available EO data.

Sentinel-1 time series have been used for several applications already. One of the principal application is the improvement of the classification of different land cover types. Thiel et al., (2009) investigated the potential of Sentinel-1 for land cover classification using multi-temporal metrics defined based on ERS and ENVISAT time series. While some authors directly use multi-temporal Sentinel-1 images in a machine learning approach using Random Forest to improve classification (Karlson et al., 2019), others explicitly calculate multi-temporal metrics of Sentinel-1 backscatter based on the time-series before using them in their classification scheme. This last approach is particularly used in agricultural applications, either to distinguish irrigated and non-irrigated crops and trees (Gao et al., 2018) or to develop crop models based on the temporal evolution of specific crops during a full season (Whelen et al., 2018). Most of these approaches use the temporal variation of the backscatter values in order to improve classification models of agricultural areas. Similar approaches were proposed for forested areas. Dostálová et al., (2018) considered a one-year time series of Sentinel-1 data over different forest types as input for forest type classification, using root mean square deviation (RMSD) values between the time series to be classified and a reference time series profile. Rüetschi et al., (2018) used two years of Sentinel-1 data for classifying deciduous and coniferous forests in Northern Switzerland, improving the Random Forest algorithm using extracted phenological information from Sentinel-1 data. For all those approaches, Sentinel-1 time series are used in a particular context for improving the classification of one particular land cover type and its subclasses.

Besides their ability to improve classification, Sentinel-1 time series can be exploited in order to retrieve phenology and seasonality information from the data. Especially, monitoring of phenological vegetation stages is of high interest in many forest and agriculture applications (Harfenmeister et al., 2019). Few authors compared time series of Sentinel-1 backscatter over different agricultural fields with diverse optical imagery and showed high correlation between NDVI and VH/VV ratio, allowing the determination of phenological phases and the possible retrieval of biophysical parameters for assimilation in crop models (Veloso et al., 2017). Other authors investigated the sensitivity of Sentinel-1 backscatter to vegetation dynamics considering different crop types and in-situ meteorological and plant information (Vreugdenhil et al., 2018; Khabbazan et al., 2019). A non-linear relationship between polarization ratio

* Corresponding author 


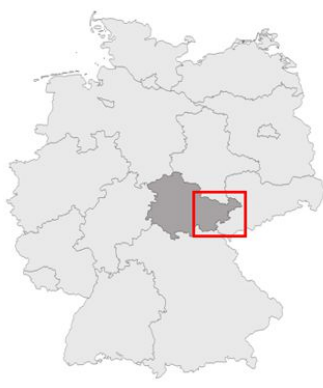

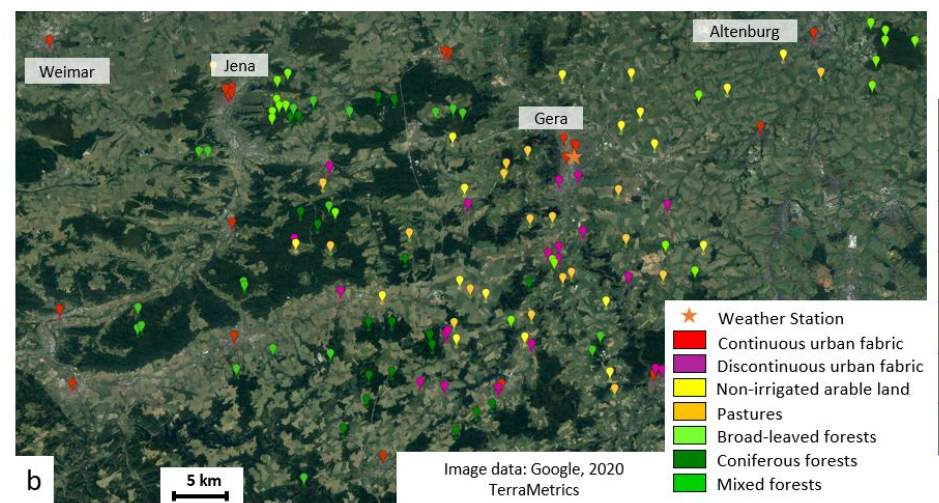

Figure 1: a) Overview of the geographical location of the study area in the Free State of Thuringia, Germany; b) reference points

for each land cover class (color-coded); c) average incidence angle in ascending and descending direction, for each class.

$\mathrm{VH} / \mathrm{VV}$, vegetation water content and vegetation structure and density was established for oilseed-rape, corn and winter cereals, with a smaller influence of soil moisture. Khabbazan et al., (2019) performed a further analysis of Sentinel-1 backscatter and coherence in order to detect key phenological dates of different crop types. An analysis using optical imagery and exhaustive insitu phenological and soil data was presented by Stendardi et al. (2019). There, the authors focused on the land cover class "meadow", retrieved from CORINE land cover.

Few approaches focused on the analysis of Sentinel-1 time series for forest seasonal monitoring. Rodionova, (2018) analyzed Sentinel-1 time series data acquired over mixed forest and vegetation-free land near Moscow for a period of one year and calculated the correlation between the observed backscatter coefficient and the dielectric properties of either trees or soil, in order to better distinguish between forested and vegetation-free areas. Changes due to the presence of snow were also quantified. Frison et al., (2018) analyzed the potential of Sentinel-1 time series for monitoring the phenology of temperate forest showing the example of a mixed forest near Paris. There, they distinguished between deciduous and coniferous tree stands. Whereas the authors observed a seasonality in the temporal profile of the deciduous trees, no seasonality was observed in the temporal profile of the coniferous trees. The ratio of VV/VH polarizations was directly compared to corresponding NDVI profiles, showing a high correlation for deciduous trees.

Existing approaches using Sentinel-1 time-series mainly focus on the assessment of the seasonality or the retrieval of key phenological phases of one specific land cover class. Furthermore, the presented approaches often consider data acquired from a single pass direction (Khabbazan et al., 2019), or combine ascending and descending data assuming comparable backscatter values from both pass directions under similar incidence angles (Frison et al., 2018).

In this study, we analyze Sentinel-1 time series of many different land cover classes together with meteorological data in order to understand the temporal behavior of radar backscatter over time and their relation to seasonal phenological effects and meteorological events. Data acquired from different pass directions are considered separately, in order to quantify the influence of the acquisition direction on the backscatter behavior for the different classes. Furthermore, different multi-temporal metrics are calculated for the different classes in order to assess their variability over time and analyze their potential separability in a multi-temporal classification-scheme. Beside the consideration of various land cover classes, the novelty of our work lies in the determination of the seasonal parameters. For the classes showing seasonal variations of the backscatter, seasonal parameters are determined using the TIMESAT software (Eklundh et al., 2016), a tool that has only been used for optical imagery until now.

This paper is structured as follows. Section 2 gives an overview of the study area and the considered satellite and auxiliary data. Section 3 explains the methodology, from the collection of the time series data to the definition of multi-temporal metrics and extraction of seasonal parameters. Section 4 presents a thorough analysis of the observed phenology depending on acquisition parameters and meteorological conditions, and shows results of the estimated temporal metrics and seasonality parameters. Finally, Section 5 discusses the seasonality of the different classes, their separability using multi-temporal and seasonal information and remaining open questions.

\section{STUDY AREA AND DATA}

The presented study is confined to the analysis of seasonality for land cover classes well represented in East-Thuringia, Germany. Whilst most of those classes could show similar backscatter behaviour in other temperate zones, further analysis should be conducted for other biomes before generalising the outcomes.

\subsection{Study Area}

The considered study area is shown in Figure 1. It comprises the Eastern part of the federal state of Thuringia, Germany. The area of about $4000 \mathrm{~km}^{2}$ encompasses several land cover classes which are typical for central Europe. The South-West of the region is characterized by forested areas, while the North-East presents more agricultural areas. Furthermore, three of the four biggest cities of Thuringia are situated in this area. The yearly temperature of this area averages to $8^{\circ} \mathrm{C}$, with mean precipitation between 600 and $650 \mathrm{~mm}$ (Bauer, 2013). Monthly average temperatures between $-1{ }^{\circ} \mathrm{C}$ and $18^{\circ} \mathrm{C}$ as well as perennial precipitations characterize the warm temperate and humid climate of this region which ensures a vegetation period of approximately seven months (Malberg, 2007).

The elevation of the region span from $150 \mathrm{~m}$ to $450 \mathrm{~m}$ a.s.l. with slopes inclinations up to approximately $15^{\circ}$ in the southern and western part of the study area.

\subsection{Data}

2.2.1 CORINE: In order to analyze possible seasonality effects on different land cover classes, seven different classes have been considered. For the sake of better reproducibility and in order to have classes showing similar biophysical characteristics in other 


\begin{tabular}{|c|c|c|c|c|c|c|}
\hline Dataset & $\begin{array}{c}\text { Direction } \\
\text { of acquisition }\end{array}$ & $\begin{array}{c}\text { Relative orbit } \\
\text { number }\end{array}$ & $\begin{array}{c}\text { Incidence } \\
\text { Angle } \\
\text { (Min-Max) }\end{array}$ & Polarisation & $\begin{array}{c}\text { Number of } \\
\text { acquisitions }\end{array}$ & $\begin{array}{c}\text { Timespan of the } \\
\text { acquisitions }\end{array}$ \\
\hline 1 & Ascending & 44 & $\begin{array}{c}34.8^{\circ}- \\
40.5^{\circ}\end{array}$ & $\mathrm{VV}+\mathrm{VH}$ & 152 & $\begin{array}{l}07 / 05 / 2016- \\
04 / 27 / 2019\end{array}$ \\
\hline 2 & Descending & 168 & $\begin{array}{c}35.3^{\circ}- \\
40.6^{\circ}\end{array}$ & $\mathrm{VV}+\mathrm{VH}$ & 158 & $\begin{array}{c}07 / 14 / 2016- \\
04 / 24 / 2019\end{array}$ \\
\hline
\end{tabular}

Table 1: Acquisition parameters of Sentinel-1 data

regions, we considered the CORINE Land Cover dataset 2018 (CLC-dataset - Feranec et al., 2010), which is provided in the framework of the Copernicus Land Monitoring Service (CLMS). The original dataset contains 44 classes distributed in a threelevel hierarchy for the whole of Europe, and is updated on a sixyear basis. The minimal mapping unit is 25 hectares with a minimal element length of 100 meters.

We considered seven common land cover classes in eastern Thuringia for our analysis (second level of CLMS): continuous and discontinuous urban fabric, non-irrigated arable land, pastures, broad-leaved, coniferous and mixed forests. Those classes were considered in order to include land cover features for which seasonality is expected to be observed (e.g. vegetation classes) and classes which should not show any seasonality effect (e.g. urban areas). Continuous urban fabric show $>80 \%$ of urban structures whereas discontinuous urban fabric is defined as having artificially surfaced area ranging from $30 \%$ to $80 \%$ of their total area coverage. Especially, small vegetated areas (e.g. gardens) are visible that could influence the backscatter behaviour. Pastures are defined as lands used at least five years for animal feed production, including herbaceous species and meadows.

In order to reduce the dataset and obtain a similar and comparable number of samples per class, we considered for each class 20 reference points, distributed across the entire study area (Figure 1b). For each of those points, the correctness of the CORINE dataset has been verified visually using Google Earth imagery and cadaster data. Furthermore, as we considered time series at these pixel positions, we ensured that the land cover type did not change during the observed time period, using both Google Earth Archive imagery and the CLC change maps provided by CLMS (Feranec et al., 2010).

2.2.2 Sentinel-1: In this study, we used Sentinel-1A \& -B ground range data acquired in the interferometric wide swath mode (IW GRD data). The time period of the acquisitions as well as specific acquisition parameters are summarized in Table 1. All acquisitions span from mid-2016 to mid-2019, in order to have acquisitions from both Sentinel-1A and $-1 \mathrm{~B}$ and therefore ensure a regular timespan between all acquisitions. Both ascending (dataset 1) and descending (dataset 2) pass directions have been considered separately in order to analyze the influence of the acquisition direction on the backscattered signal. For both datasets, the seasonality has been analyzed for polarizations VV and $\mathrm{VH}$, respectively.

2.2.3 Auxiliary Data: Meteorological data from the weather station Gera-Leumnitz (Figure 1b) has been considered in this analysis. In particular, averaged daily precipitation and daily air temperature at $2 \mathrm{~m}$ above the ground level were compared to the backscatter values. These data are presented together with the backscatter time series in Figure 3.

To better interpret the high variability of the backscatter values, no specific data removal has been performed -neither on the backscatter signals nor on the meteorological data. Especially, variations due to frost are still observable. It is noticeable that more precipitation occurred during summer 2017 than during the dry summer of 2018, for which the air temperature maxima were $5^{\circ} \mathrm{C}$ above the highest temperatures of 2017 .

\section{METHODOLOGY}

In this section, we describe how we extracted backscatter time series for defined geographic reference points using Google Earth Engine and how we evaluated the seasonality of the time series.

\subsection{Collection of data from Google Earth Engine}

The times series of Sentinel-1 data have been collected using the Google Earth Engine Code Editor interface. The CLC dataset was loaded as an "asset" and corresponding Sentinel-1 backscatter time series have been extracted for the reference points of each class at defined geographic locations. The Sentinel-1 data available on Google Earth Engine are given as pre-processed radar backscatter coefficients $\left(\sigma^{0}\right)$ in decibel $(\mathrm{dB})$. The following pre-processing steps have been applied to the data (GEE 2019), as implemented in the Sentinel-1 Toolbox:

- orbit file application

- GRD border noise removal

- thermal noise removal

- radiometric calibration to $\sigma^{0}$

- geometric terrain correction

The final backscatter coefficient $\sigma^{0}$ is converted to $\mathrm{dB}$ after preprocessing.

It should be mentioned that no terrain flattening is performed during this processing, due to artefacts on mountain slopes (GEE, 2019). In this study, we focus on the time series dynamics and assumed that the considered reference patches are comparable, as they are situated on mainly flat terrain. Moreover, we can assume that terrain stays static along time series analyses.

In order to get a robust estimation of the backscatter for each date and class, and to reduce speckle, a spatial averaging of the backscatter values within a $100 \times 100$ meter window around each reference point has been performed. Therefore, a reference patch of one hectare (10x10 Sentinel-1 GRD pixels) has been considered for each reference point. Using Google Earth imagery, it was also ensured that the reference patches cover only the desired land cover class, so that the mean backscatter intensity is not biased by heterogeneity in land cover. An overview of the quality and variance of the selected reference patches is given in Section 4.1.

\subsection{Multi-temporal metrics}

For the analysis of the time series, different acquisition parameters were considered and compared.

First, the difference between ascending and descending acquisitions has been investigated, in order to assess the impact of variable orbits on the backscatter behavior and the resulting consequences regarding mixing the orbits for more detailed multi-temporal applications. Second, the difference between both available polarizations $\mathrm{VV}$ and $\mathrm{VH}$ has been analyzed. Especially, vegetated areas have been investigated more thoroughly in order to better understand which scattering mechanisms occur at which phenological state.

In order to quantify the observed differences between the analyzed time series of the different land cover classes and their seasonal trends, two different methods have been used: multitemporal descriptive statistics (Section 3.2.1) and determination of specific seasonality parameters using TIMESAT (Section 3.2.2). 


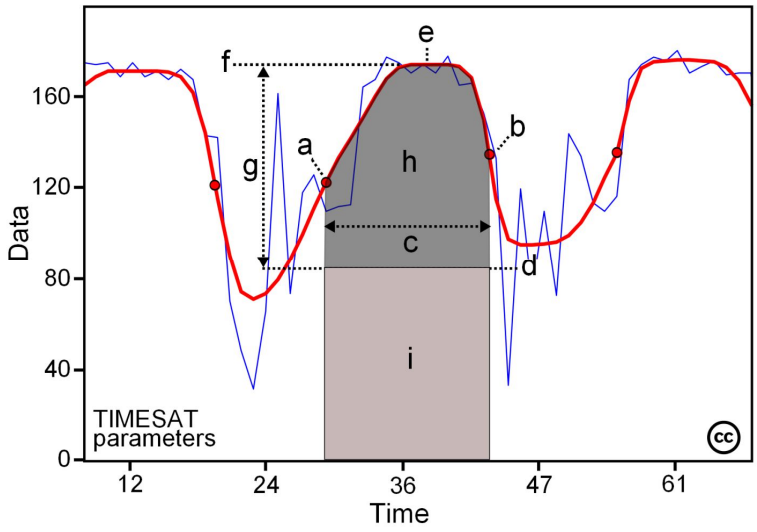

Figure 2: Seasonality parameters generated in TIMESAT: (a) beginning of season (SOS), (b) end of season (EOS), (c) length of season (LOS), (d) base value, (e) time of middle of season, (f) maximum value, (g) amplitude (AOS), (h) small integrated value, $(\mathrm{h}+\mathrm{i})$ large integrated value. (Source: Eklundh et al., 2016)

3.2.1 Multi-temporal statistics: Different multi-temporal statistical parameters were calculated based on the averaged backscatter values of the 20 reference patches, for each class. In the following, we call $\mu_{\sigma, r}$ the arithmetical mean of the backscatter values $\sigma^{0}$ within a reference patch $r$, and $\mu_{d, c}$ the mean of all $\mu_{\sigma, r}$ at a specific date $d$ for a specific land cover class c. $N_{T}$ is the total number of acquisitions.

$$
\mu_{\sigma, r}=\frac{1}{n} \cdot \sum_{i=1}^{n} \sigma_{i}^{0}
$$

The parameter $i$ corresponds to the considered pixel within the reference patch $(i \in[1: n, n=100])$.

$$
\mu_{d, c}=\frac{1}{20} \cdot \sum_{r=1}^{20} \mu_{\sigma, r}
$$

The calculated multi-temporal statistics can be resumed as follows: $-$

Multi-temporal mean $\mu_{T, c}$

$$
\mu_{T, c}=\frac{1}{N_{T}} \cdot \sum_{d=1}^{N_{T}} \mu_{d, c}
$$

Multi-temporal standard deviation

$$
\sigma_{T, c}=\sqrt{\frac{1}{N_{T}-1} \cdot \sum_{d=1}^{N_{T}}\left(\mu_{d, c}-\mu_{T, c}\right)^{2}}
$$

Temporal min and max and amplitude

$$
\begin{gathered}
\min _{T}=\min \left(\mu_{d, c}, d \in\left[1, N_{T}\right]\right) \\
\max _{T}=\max \left(\mu_{d, c}, d \in\left[1, N_{T}\right]\right) \\
A_{T}=\operatorname{abs}\left(\max _{T}-\min _{T}\right)
\end{gathered}
$$

Radar Vegetation Index $(R V I)$

$R V I$ was defined by (Charbonneau et al., 2005) for the dual polarization case as:

$$
R V I=\frac{4 \sigma_{V H}^{0}}{\sigma_{V V}^{0}+\sigma_{V H}^{0}}
$$

Multi-temporal mean $\mu_{R V I}$ and standard deviation $\sigma_{R V I}$ of the $R V I$ values were calculated in order to determine if multitemporal $R V I$ can help to better separate the vegetation classes. The RVI calculation was performed on linear (no $\mathrm{dB}$ ) backscatter values and transformed back to $\mathrm{dB}$ for representation in Figure 3.

3.2.2 Seasonality parameters: In order to better estimate the seasonality of the different classes and determine the duration of seasons, the TIMESAT software version 3.3 (TIMESAT, 2017) was used. Detailed information about software functionality can be found in (Eklundh et al, 2016). This tool allows the automatic determination of relevant seasonality parameters such as beginning, end, duration and amplitude of a season. Those parameters are represented schematically in Figure 2. For the time series, a season is defined as a sinusoidal waveform of the backscatter values with a specific amplitude. A maximum of two seasons per year is detectable with TIMESAT. The principal parameters considered in this study are Start-of-Season (SOS), End-of-Season (EOS), Length of Season (LOS) and Amplitude of the Seasonality (AOS).

Using the time series of the averaged backscatter values of the reference patches for each class, different functions (asymmetric Gaussian, double logistic function and adaptive Savitzky-Golay filtering) are fitted to the data with TIMESAT with least-square methods, the final parameters of the fitted functions defining the seasonality. Originally developed for the analysis of NDVI time series, it works with any kind of time series, provided the observation period is larger than two years. In this work, we considered two models out of the three proposed for the final estimation of the seasonality parameters. Asymmetric Gaussian and double logistical fits outperformed the Savitzky-Golay fitting. The latter provides a smoothed representation of the original data but tends to overfit the data and finds seasonalities where data gaps or small temporal changes occur, which are not related to phenological states. Prior to fitting, we smoothed the time series using a $5 \times 1$ averaging moving window and eliminated acquisitions under freezing conditions where air temperatures less than $-2^{\circ} \mathrm{C}$ occurred in the three hours before acquisition.

\section{OBSERVED SEASONALITY IN TIME SERIES}

This section shows the observed time series of Sentinel-1 averaged backscatter $\left(\mu_{d, c}\right)$ for the different land cover classes and analyzes their seasonality. The Sentinel-1 backscatter values for each acquisition date are averaged for each class over the 20 reference patches. The different time series are represented in Figure 3, together with meteorological information. Figure $3 \mathrm{~h}$ summarizes the multi-temporal statistics for relevant land cover classes, for the descending configuration. The calculated seasonality parameters with TIMESAT are shown in Table 3.

\subsection{Quality of the selected reference patches}

In order to assess the quality and homogeneity of the selected reference patches, the variance of each considered class has been calculated (Section 3.1). For the descending direction in both polarizations, Table 2 gives the standard deviation of the backscatter for the 20 reference patches of each class at each acquisition date, averaged for all acquisition dates. It provides an indication about the homogeneity of the backscatter values of each class. The corresponding averaged backscatter values can be found in Table 3 . 


\begin{tabular}{|c|c|c|c|c|c|c|c|}
\hline Class & $\begin{array}{c}\text { Continuous } \\
\text { urban }\end{array}$ & $\begin{array}{c}\text { Discontinuous } \\
\text { urban }\end{array}$ & $\begin{array}{c}\text { Non- } \\
\text { Irrigated } \\
\text { arable land }\end{array}$ & Pasture & $\begin{array}{c}\text { Broad- } \\
\text { leaved } \\
\text { Forest }\end{array}$ & $\begin{array}{c}\text { Coniferous } \\
\text { Forest }\end{array}$ & $\begin{array}{c}\text { Mixed } \\
\text { Forest }\end{array}$ \\
\hline STD VV & $1.87 \mathrm{~dB}$ & $2.25 \mathrm{~dB}$ & $1.85 \mathrm{~dB}$ & $1.75 \mathrm{~dB}$ & $0.90 \mathrm{~dB}$ & $0.91 \mathrm{~dB}$ & $1.52 \mathrm{~dB}$ \\
\hline STD VH & $2.07 \mathrm{~dB}$ & $2.10 \mathrm{~dB}$ & $2.28 \mathrm{~dB}$ & $1.81 \mathrm{~dB}$ & $0.95 \mathrm{~dB}$ & $0.82 \mathrm{~dB}$ & $1.47 \mathrm{~dB}$ \\
\hline
\end{tabular}

Table 2: Standard deviation of the backscatter values within each class, averaged for all acquisition dates

The land cover classes showing the lowest standard deviation are the homogeneous forest classes $(<1 \mathrm{~dB})$. The class "mixed forest" shows a slightly higher standard deviation $(\approx 1.5 \mathrm{~dB})$, probably due to the different tree types contained. The "nonirrigated arable land" class shows a higher standard deviation, due to the different crop types and farming practices within these areas. The class "discontinuous urban fabric" also shows a high standard deviation, which can be related to the different land cover types within these areas (e.g. man-made infrastructure and small gardens). The considered reference patches are assumed to be homogeneous and representative for their class.

\subsection{Statistical Analysis of the time series}

This subsection describes the different backscatter time series and corresponding estimated statistics. Figure 3 shows the times series of both polarizations for both pass direction as well as $R V I$ and the ratio $\mathrm{VH} / \mathrm{VV}$ for the descending direction only, in order to keep the figures readable. Each main land cover class is described separately.

4.2.1 Continuous and discontinuous urban fabric: For urban and sub-urban areas, only small variations can be observed in the backscatter values over time $\left(\sigma_{T, c}\right.$ of $0.2 \mathrm{~dB}$ and $A_{T}$ of 1.5 $\mathrm{dB}$ for continuous and $\sigma_{T, c}$ of $0.4 \mathrm{~dB}$ and $A_{T}$ of $1.9 \mathrm{~dB}$ for discontinuous urban fabric). This is due to the persistent backscatter properties of most man-made objects, which tend to be stable over time. A very slight seasonal variation of the backscatter values can be observed for the sub-urban class for each acquisition parameter $\left(A_{T}\right.$ of $2.6 \mathrm{~dB}$ for desc $\left.\mathrm{VH}\right)$, which can be explained by the presence of vegetation in areas with low building density (e.g. allotment gardens, small woods).

For both classes, a strong difference of $1.1-1.4 \mathrm{~dB}$ in the backscatter values of the $\mathrm{VV}$ polarization can be observed between ascending and descending acquisitions (Fig. 3a and 3b), where the backscatter values for ascending are systematically higher than the one for descending.

Regarding the $\mathrm{VH}$ polarization, not much difference can be observed between ascending and descending acquisitions for the sub-urban class (Fig. 3b). For the urban class, the backscatter values for $\mathrm{VH}$ polarization in descending orbit direction seems systematically slightly higher than for the VH polarization in ascending direction $\left(\Delta \mu_{T, c}\right.$ of $0.4 \mathrm{~dB}$, Fig. 3a).

For an extraction of urban areas based on backscatter values, the VV polarization seems best suited: the multi-temporal observations show a VV backscatter value at least $1.5 \mathrm{~dB}$ higher than for any other land cover class (Fig. 3h).

4.2.2 Non-irrigated arable land and pasture areas: Both pastures and agricultural areas show seasonal variations in backscatter $\left(A_{T}\right.$ of $11.8 \mathrm{~dB}$ for agricultural areas and of $9.4 \mathrm{~dB}$ for pastures in descending VH, Fig. 3h). For pastures, the backscatter values in VH drop during wintertime $\left(\min _{T}=-26.7\right.$ $\mathrm{dB}$ for desc $\mathrm{VH}$, with lower backscatter in February/March), whereas for the VV polarization, the backscatter values drop during spring/summer $\left(\min _{T}=-16.0 \mathrm{~dB}\right.$ for desc VV with lower backscatter in Mai/June except for one outlier in February 2018,
Fig. 3d). Considering the year 2018, the VH backscatter values during summer do not rise as far as in the year 2017. Summer 2018 was marked by severe drought in Germany and especially in eastern Thuringia, as shown by the German Drought Monitor (Zink et al., 2016). It is visible that no or very little precipitation occurs between June and September 2018, whereas the year 2017 was characterized by more precipitation events during this period. As the water content in plants and soil diminishes through drought, this induces a drop in the backscatter values as they depend on dielectric plant properties. The VV polarization seems less affected by drought, as VV values rises equally in the years 2017 and 2018.

For the backscatter time series from agricultural areas, a strong seasonality can be observed for the $\mathrm{VV}$ polarization $\left(A_{T}=\right.$ $7.6 \mathrm{~dB}$, Fig. $3 \mathrm{c} \& 3 \mathrm{~h}$ ). The backscatter values in agricultural areas depend highly on the considered crop and its phenological cycle (Khabbazan et al. 2019), which depends on the specific farming and the applied tillage practices. Due to missing information, this specific analysis was not further pursued in this study.

For the class "pasture", a slightly higher backscatter can be observed for the ascending direction especially in $\mathrm{VH}$ polarization $\left(\mu_{T, c}\right.$ is $0.6 \mathrm{~dB}$ higher for asc $\mathrm{VH}$ than for desc $\mathrm{VH}$, Fig. 3d).

For both classes, RVI and the ratio VH/VV show very similar behaviors over time (see Fig. $3 \mathrm{c}$ and $3 \mathrm{~d}$ ) due to their similar calculus. Especially, an increase of both values during spring and a decrease during fall is clearly observable. Compared to other classes, $\sigma_{R V I}$ is higher, permitting a better distinction of those classes based on RVI.

4.2.3 Broad-leaved, coniferous and mixed forests: For the three forest classes (broad-leaf, coniferous \& mixed), ascending and descending direction of acquisitions exhibit a similar behavior of the backscatter time series. A slightly higher backscatter can be observed for the ascending direction especially in $\mathrm{VH}$ polarization $\left(\mu_{T, c}\right.$ up to $0.5 \mathrm{~dB}$ higher, not shown here). All three forest classes show seasonality effects. However, each class shows individual time series behavior so that it is analyzed separately in the following.

Starting with the broad-leaved forest, two specific recurring effects can be identified, more pronounced for the $\mathrm{VH}$ polarization. Firstly, a drop of the backscatter values, accompanied by a stronger dispersion of the backscatter values, occurs during the winter months $\left(\min _{T}=-17.7 \mathrm{~dB}\right.$ for desc $\mathrm{VH}$, Fig. 3e \&h). Secondly, during summer, a decrease of the backscatter values is observable (from approx. $-13 \mathrm{~dB}$ in February/March to approx. $-16 \mathrm{~dB}$ in August/September). The first effect can be explained by the presence of snow or frost on the tree biomass, like branches (Khabbazan et al., 2019), which is in accordance with the measured air temperatures and precipitation at this time of the year, as well as reduced water content in the canopy during winter. The second effect (decrease of the backscatter between winter and summer) starts directly after winter, when buds form and build leaves. The denser the canopy, the less the signal can penetrate, meaning that during summer, most of the incoming signal is scattered directly at the top of the canopy. During spring and fall, when leaves are forming or falling, the signal can penetrate more into the canopy and volume backscattering might be pronounced, providing a higher VH-backscatter. Additionally, the water content in leaves decreases during dry summers, leading to a decrease of the backscatter values (water stress situation). Some higher peaks also occur during the summer months, due to the presence of water after precipitation (interception), as seen particularly after the intensive rain event in mid-August 2017 (Fig. 3e).

The coniferous forests show a strong and regular seasonality in both polarizations, with variations of the backscatter values up to 


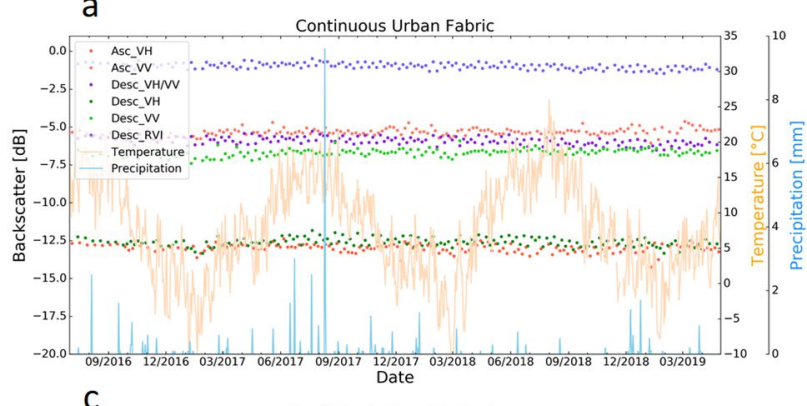

C
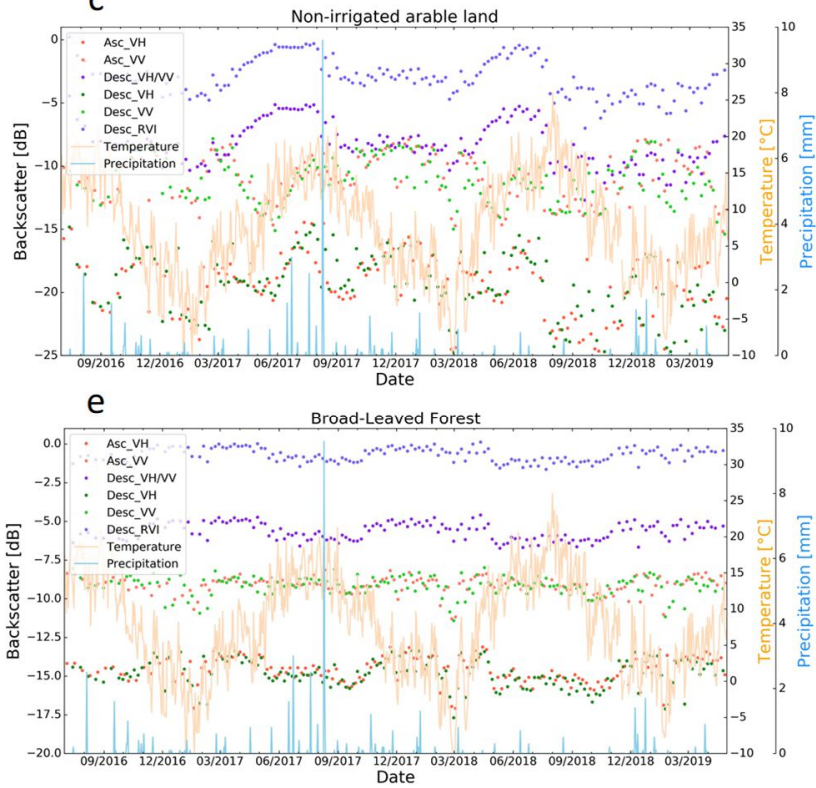

g

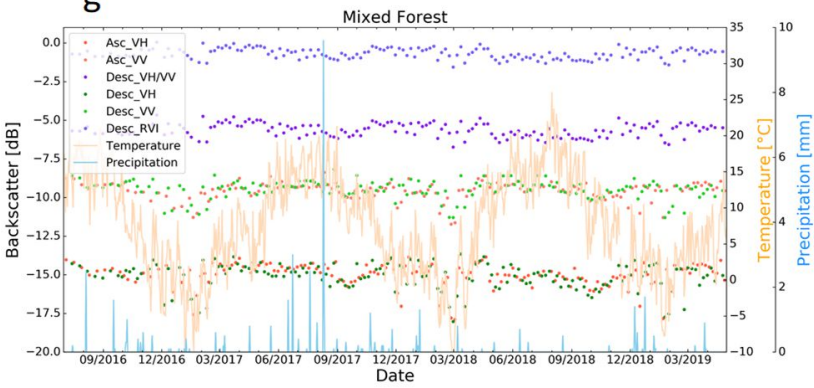

b
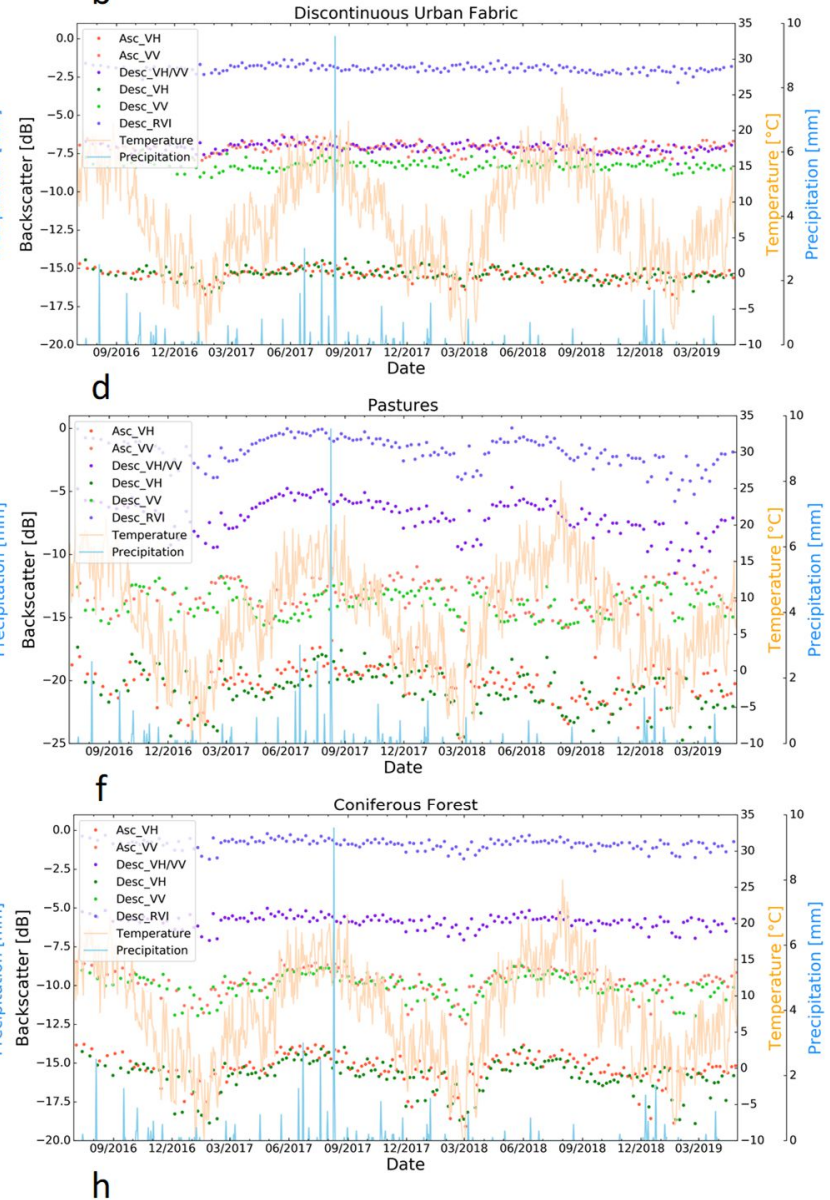

$\mathrm{h}$

\begin{tabular}{|c|c|c|c|c|c|c|c|c|}
\hline Class & Polarisation & $\mu_{T, c}$ & $\sigma_{T, c}$ & $A_{T}$ & $\min _{T}$ & $\max _{T}$ & $\mu_{R V I}$ & $\sigma_{R V I}$ \\
\hline $\begin{array}{c}\text { Continuous } \\
\text { urban }\end{array}$ & $\begin{array}{c}\mathrm{VV} \\
\mathrm{VH} \\
\mathrm{VH} / \mathrm{VV}\end{array}$ & $\begin{array}{l}-6.7 \mathrm{~dB} \\
-12.6 \mathrm{~dB} \\
-5.9 \mathrm{~dB}\end{array}$ & $\begin{array}{l}0.2 \mathrm{~dB} \\
0.3 \mathrm{~dB} \\
0.3 \mathrm{~dB}\end{array}$ & $\begin{array}{l}1.5 \mathrm{~dB} \\
1.5 \mathrm{~dB} \\
1.2 \mathrm{~dB}\end{array}$ & $\begin{array}{l}-7.4 \mathrm{~dB} \\
-13.3 \mathrm{~dB} \\
-6.5 \mathrm{~dB}\end{array}$ & $\begin{array}{r}-5.9 \mathrm{~dB} \\
-11.8 \mathrm{~dB} \\
-5.3 \mathrm{~dB}\end{array}$ & $-0.9 \mathrm{~dB}$ & $0.0 \mathrm{~dB}$ \\
\hline $\begin{array}{l}\text { Discontinuous } \\
\text { urban }\end{array}$ & $\begin{array}{c}\mathrm{VV} \\
\mathrm{VH} \\
\mathrm{VH} / \mathrm{VV}\end{array}$ & $\begin{array}{c}-8.2 \mathrm{~dB} \\
-15.4 \mathrm{~dB} \\
-7.1 \mathrm{~dB}\end{array}$ & $\begin{array}{l}0.3 \mathrm{~dB} \\
0.4 \mathrm{~dB} \\
0.3 \mathrm{~dB}\end{array}$ & $\begin{array}{l}1.9 \mathrm{~dB} \\
2.6 \mathrm{~dB} \\
1.7 \mathrm{~dB}\end{array}$ & $\begin{array}{c}-9.0 \mathrm{~dB} \\
-17.0 \mathrm{~dB} \\
-8.2 \mathrm{~dB}\end{array}$ & $\begin{array}{c}-7.2 \mathrm{~dB} \\
-14.4 \mathrm{~dB} \\
-6.4 \mathrm{~dB}\end{array}$ & $-1.9 \mathrm{~dB}$ & $0.0 \mathrm{~dB}$ \\
\hline $\begin{array}{l}\text { Non-Irrigated } \\
\text { arable land }\end{array}$ & $\begin{array}{c}\mathrm{VV} \\
\mathrm{VH} \\
\mathrm{VH} / \mathrm{VV}\end{array}$ & $\begin{array}{l}-11.1 \mathrm{~dB} \\
-19.4 \mathrm{~dB} \\
-8.3 \mathrm{~dB}\end{array}$ & $\begin{array}{l}1.8 \mathrm{~dB} \\
2.6 \mathrm{~dB} \\
1.7 \mathrm{~dB}\end{array}$ & $\begin{array}{r}7.6 \mathrm{~dB} \\
11.8 \mathrm{~dB} \\
8.3 \mathrm{~dB}\end{array}$ & $\begin{array}{l}-15.4 \mathrm{~dB} \\
-26.5 \mathrm{~dB} \\
-12.7 \mathrm{~dB}\end{array}$ & $\begin{array}{r}-7.8 \mathrm{~dB} \\
-14.7 \mathrm{~dB} \\
-4.4 \mathrm{~dB}\end{array}$ & $-2.7 \mathrm{~dB}$ & $0.2 \mathrm{~dB}$ \\
\hline Pasture & $\begin{array}{c}\mathrm{VV} \\
\mathrm{VH} \\
\mathrm{VH} / \mathrm{VV}\end{array}$ & $\begin{array}{l}-13.9 \mathrm{~dB} \\
-20.9 \mathrm{~dB} \\
-7.0 \mathrm{~dB}\end{array}$ & $\begin{array}{l}1.1 \mathrm{~dB} \\
1.8 \mathrm{~dB} \\
1.4 \mathrm{~dB}\end{array}$ & $\begin{array}{l}4.2 \mathrm{~dB} \\
9.4 \mathrm{~dB} \\
6.8 \mathrm{~dB}\end{array}$ & $\begin{array}{l}-16.0 \mathrm{~dB} \\
-26.7 \mathrm{~dB} \\
-11.5 \mathrm{~dB}\end{array}$ & $\begin{array}{l}-14.7 \mathrm{~dB} \\
-17.4 \mathrm{~dB} \\
-4.7 \mathrm{~dB}\end{array}$ & $-1.6 \mathrm{~dB}$ & $0.2 \mathrm{~dB}$ \\
\hline $\begin{array}{l}\text { Broad-leaved } \\
\text { Forest }\end{array}$ & $\begin{array}{c}\mathrm{VV} \\
\mathrm{VH} \\
\mathrm{VH} / \mathrm{VV}\end{array}$ & $\begin{array}{r}-9.2 \mathrm{~dB} \\
-14.8 \mathrm{~dB} \\
-5.7 \mathrm{~dB}\end{array}$ & $\begin{array}{l}0.0 \mathrm{~dB} \\
0.9 \mathrm{~dB} \\
0.6 \mathrm{~dB}\end{array}$ & $\begin{array}{l}3 . \mathrm{dB} \\
4.5 \mathrm{~dB} \\
2.2 \mathrm{~dB}\end{array}$ & $\begin{array}{l}-11.4 \mathrm{~dB} \\
-17.7 \mathrm{~dB} \\
-6.8 \mathrm{~dB}\end{array}$ & $\begin{array}{r}-8.0 \mathrm{~dB} \\
-13.2 \mathrm{~dB} \\
-4.6 \mathrm{~dB}\end{array}$ & $-0.7 \mathrm{~dB}$ & $0.1 \mathrm{~dB}$ \\
\hline $\begin{array}{c}\text { Coniferous } \\
\text { Forest }\end{array}$ & $\begin{array}{c}\mathrm{VV} \\
\mathrm{VH} \\
\mathrm{VH} / \mathrm{VV}\end{array}$ & $\begin{array}{l}-10.0 \mathrm{~dB} \\
-15.9 \mathrm{~dB} \\
-5.9 \mathrm{~dB}\end{array}$ & $\begin{array}{l}0.8 \mathrm{~dB} \\
1.1 \mathrm{~dB} \\
0.4 \mathrm{~dB}\end{array}$ & $\begin{array}{l}3.6 \mathrm{~dB} \\
4.9 \mathrm{~dB} \\
2.1 \mathrm{~dB}\end{array}$ & $\begin{array}{l}-12.0 \mathrm{~dB} \\
-18.9 \mathrm{~dB} \\
-7.1 \mathrm{~dB}\end{array}$ & $\begin{array}{r}-8.4 \mathrm{~dB} \\
-14.0 \mathrm{~dB} \\
-5.0 \mathrm{~dB}\end{array}$ & $-0.8 \mathrm{~dB}$ & $0.1 \mathrm{~dB}$ \\
\hline Mixed Forest & $\begin{array}{c}\mathrm{VV} \\
\mathrm{VH} \\
\mathrm{VH} / \mathrm{VV}\end{array}$ & $\begin{array}{r}-9.5 \mathrm{~dB} \\
-15.1 \mathrm{~dB} \\
-5.6 \mathrm{~dB}\end{array}$ & $\begin{array}{l}0.6 \mathrm{~dB} \\
0.8 \mathrm{~dB} \\
0.4 \mathrm{~dB}\end{array}$ & $\begin{array}{l}3.1 \mathrm{~dB} \\
4.4 \mathrm{~dB} \\
2.1 \mathrm{~dB}\end{array}$ & $\begin{array}{l}-11.3 \mathrm{~dB} \\
-18.0 \mathrm{~dB} \\
-6.7 \mathrm{~dB}\end{array}$ & $\begin{array}{r}-8.2 \mathrm{~dB} \\
-13.6 \mathrm{~dB} \\
-4.7 \mathrm{~dB}\end{array}$ & $-0.7 \mathrm{~dB}$ & $0.1 \mathrm{~dB}$ \\
\hline
\end{tabular}

Figure 3: Time series profiles of Sentinel-1 C-band backscatter values and meteorological conditions for CORINE land cover classes of Thuringia: a) continuous urban fabric; b) discontinuous urban fabric; c) non-irrigated arable land; d) pastures; e) broadleaved forest; f) coniferous forest; g) mixed forest; $h$ ) principal multi-temporal metrics for the descending direction

$3.6 \mathrm{~dB}$ between winter and summer (Fig. $3 \mathrm{f} \& 3 \mathrm{~h}$ ). Here, we can also observe a drop of the backscatter values during winter $\left(\min _{T}\right.$ $=-18.9 \mathrm{~dB}$ for desc $\mathrm{VH}$ ) with a stronger dispersion of the values. This could have the same reason as for the broad-leaved forests, with snow or frost being on the needles and branches. Contrary to the deciduous forest, an increase of the backscatter values is observed during summer (Fig. 3f).

The mixed forests show seasonal characteristics of both previous classes, except for the time series profiles of 2018, which resemble more the broad-leaved forests. A visual inspection of the reference patches indicated that deciduous trees prevail in the chosen patches. In general, the backscatter shows a more constant behavior in the summer, coming from an averaging effect caused by the lower backscatter values from the broad-leaved forests and the higher backscatter values from the coniferous forests.
Concerning RVI and the ratio VH/VV, they only show moderate seasonal variations for the broad leaved forests (Fig. 3e) and no distinct variations for the other forest classes (Fig. $3 \mathrm{f} \& 3 \mathrm{~g}$ ). In general, $\mu_{R V I}$ is higher for the forests classes than for all other classes (Fig. 3h), which would allow a classification based on RVI.

\subsection{Calculated Seasonality with TIMESAT}

Table 3 shows the calculated seasonality with TIMESAT for the three forest classes in descending $\mathrm{VH}$ acquisitions, as it shows for all classes the strongest seasonal variations (Fig. $3 \mathrm{~h}, A_{T}$ ). The seasonality parameters are calculated for each year based on the chosen models in TIMESAT (Section 3) and an average of both models is given in Table 3. In this study, it was only possible to 


\begin{tabular}{|c|c|c|c|c|}
\hline Class & LOS & SOS & EOS & AOS \\
\hline $\begin{array}{c}\text { Broad-leaved Forest } \\
2017 / 2018\end{array}$ & 6 months & October 2017 & April 2018 & $1.4 \mathrm{~dB}$ \\
\hline Coniferous Forest 2017 & 8 months & March 2017 & October 2017 & $1.6 \mathrm{~dB}$ \\
\hline Coniferous Forest 2018 & 6 months & March 2018 & September 2018 & $1.5 \mathrm{~dB}$ \\
\hline Mixed Forest 2017/2018 & 11 months & October 2017 & August 2018 & $1.0 \mathrm{~dB}$ \\
\hline
\end{tabular}

Table 3: calculated seasonal parameters of the tree classes.

analyze the seasonality parameters for the years 2017 and 2018, as those where the only two full years of observations. For the broad-leaved and mixed forest classes, only one season has been detected. TIMESAT generally detects the SOS when the signal increases and EOS when the signal decreases. As for both classes, backscatter decreases during summer and increases during winter, the seasonality parameters that have been estimated correspond to the winter 2017/2018, when the deciduous trees are under leaf-off conditions. The estimated SOS and LOS between October and April corresponds well to the bare-leaved period in the region. The estimated EOS for mixed forest in August 2018 does not show a clear tendency, probably because of the presence of both broad-leaved and coniferous trees in this class. The estimated seasonal parameters for the coniferous forest concur for both years with the observation of Section 4.2.3. For the year 2018, the EOS happens a month earlier than in 2017. This can be explained by earlier desiccation and leaf loss due to the extreme drought of 2018.

In general, we observe an underestimation of about $2 \mathrm{~dB}$ of the AOS compared to the estimated $A_{T}$. This is probably due to the model fits that smooth the extrema of the time series.

\section{DISCUSSION}

In this section, we discuss the observed seasonal signatures and the influence of acquisition parameters together with findings from literature, and assess the possibility of multi-temporal observations to distinguish different land cover classes. Furthermore, we identify remaining research questions.

\subsection{Seasonal signatures}

Most of the vegetation classes show strong seasonal variations. Concerning non-irrigated arable land and pastures, RVI time series indicate the phenological stages of plant growth, increasing during spring, stabilizing during summer and dropping during fall. The tree classes show different behavior depending on the tree species. Contrary to (Frison et al., 2018), we observe a strong seasonality for coniferous trees, which is opposite in time to the seasonality of deciduous trees. This may have two possible explanations. Even though most coniferous trees do not drop their needles over winter in general, the water content inside the needles changes according to water availability, transpirational needs due to temperature changes (freezing) and solar irradiation. Needle desiccate during winter with the desiccation reaching a maximum in spring (Roy, Hinckley, 2013). A higher water content in the needles during summer could explain the stronger backscatter observed in this period but should be further examined in a dedicated experiment. The second possibility would be the stronger penetration of the signal into the canopy due to a sparser distribution of the trees and therefore the interaction of the signal with understory vegetation (Dostálová et al. 2016). A specific investigation of the influence of the understory for this area will be conducted in future work.

\subsection{Influence of acquisition parameters}

Several differences of the time series between the different pass directions are observed.
5.2.1 Ascending VV systematically higher than descending VV in urban areas: as the VV backscatter might originate from double-bounce interaction with vertical structures such as building walls, a further analysis of the orientation of the buildings toward the sensor in the considered patches should be made in order to assess if this could be the reason for the observed offset. (Koppel et al., 2017) showed already the dependence of backscatter on different building parameters (height, alignment, material, density and shape of buildings), the building alignment having a cyclical effect on the backscatter intensity (cycle of $90^{\circ}$ alignment angle). Ascending and descending acquisitions show different heading angles, leading to different alignment of buildings in both pass directions. The authors also mentioned the influence of different incidence angles (from ascending and descending orbit directions) on the backscatter values. The considered urban areas in this work are spatially well distributed in the study area, with an averaged incidence angle difference between ascending and descending orbit directions of approx. $1^{\circ}$ (Fig. 1c). Few reference patches with strong double bounce effect in one particular pass direction could influence the averaged backscatter, therefore the building alignment within each reference patch will be investigated in future work focusing on incidence angle and pass direction.

5.2.2 Higher ascending backscatter in pastures and forest classes: ascending acquisitions are acquired for this region at 16:59 UTC and descending acquisitions at 05:25 UTC. Some investigations about the effects of dew on the backscatter in Lband have been performed in (Riedel et al., 2002) and (Beale et al., 2019). For C-Band, (Gillepsie et al., 1990) observed an increase of the backscatter for wheat and mentioned that the different ways in which dew is distributed on the plants could help with crop type identification by radar. More likely in our case, diurnal variations of the dielectric properties of the plants could have an influence on the backscatter and should be investigated. The work of van Emmerik et al. (2015) showed at the example of maize crop the dependency of the backscatter on the diurnal variation in vegetation water content and soil moisture, at different frequencies and incidence angles. To our knowledge, no such investigation exist for different tree types. Another reason for the observed offset between ascending and descending backscatter could be the different signal pathways through the vegetation caused by the different incidence angles. The selected reference patches for both ascending and descending acquisitions are located approximately in the middle of the scenes. A closer investigation of the specific incidence angles for each reference patch and orbit direction (Fig. 1c) indicates that for the deciduous tree class, the incidence angle was in general higher in ascending as in descending direction (approx. $1^{\circ}$ ). For the coniferous tree class, the incidence angle of descending was in general higher as in ascending direction (approx. $1^{\circ}$ ). As for both classes the ascending backscatter in $\mathrm{VH}$ shows slightly higher values than for descending, no direct conclusion can be made and further analysis concerning the different aspect angles of ascending and descending viewing geometry onto the tree stand is needed.

\subsection{Statistical metrics and seasonality parameters}

For this study, different statistical metrics have been calculated for the different classes (Section 3.2) in order to determine which are best suited for multi-temporal classification. While the principal land cover classes (urban, forest and other vegetation) can be well separated based on the multi-temporal mean, the distinction of sub-classes (e.g. deciduous, coniferous forest and mixed forest) requires further metrics. Urban and suburban classes could be distinguished using $\mu_{T, c}$ in VH. However, $\mu_{T, c}$ 
for the sub-urban class in $\mathrm{VH}$ is very similar to $\mu_{T, c}$ in $\mathrm{VH}$ for the tree classes. The mean RVI or $A_{T}$ could therefore be used to separate the discontinuous urban classes from the forest classes. The arable and pasture areas could be separated based on their multi-temporal standard deviation in $\mathrm{VH}$ or their amplitude in VV (Fig. 3h). For the class "non-irrigated arable land", seasons are better observable using RVI (Fig. 3c). Estimating seasonality parameters on RVI with TIMESAT would therefore further help to distinguish between the classes "pastures" and "Non-irrigated arable land". The distinct identification of the different forest classes seem to be possible only using the seasonality parameters estimated with TIMESAT: LOS and AOS could be used to distinguish mixed forest from the homogeneous forest types, and the SOS and EOS could be used to distinguish coniferous from deciduous forest, as both show opposite temporal variations in a year.

For better comparison with other approaches, the ratio VH/VV and corresponding multi-temporal statistics have been calculated. It shows high similarity with the $R V I$, thus additional calculus did not provide additional information. The ratio VV/VH would be the exact mirror image of $\mathrm{VH} / \mathrm{VV}$ and is particularly interesting for analyzing the relationship between the backscatter of broadleaved forest and NDVI, as they behave similarly (Frison et al., 2018).

\section{CONCLUSION}

In this study, we performed an unprecedented analysis of Sentinel-1 backscatter time series. While existing approaches focused mainly on one specific land cover class, we investigated seven major land cover classes well represented all over Europe. For those classes, we estimated multi-temporal metrics and seasonality parameters using TIMESAT over a period of three years in order to both better understand seasonal variation of the signal and to define suitable metrics for multi-temporal classification approaches.

We have shown that the principal land cover classes are well separable using multi-temporal metrics such as multi-temporal mean, backscatter amplitude and standard deviation, but that the individual identification of different forest classes requires further information from derivate parameters such as RVI and seasonal parameters that were determined using TIMESAT. We also confirmed that different orbit directions should be considered individually as the resulting backscatter value at a specific location is influenced by the incidence and aspect angles. Based on these outcomes, classification of major land cover classes and sub-classes can be conducted more effectively. In future work, we will investigate in more detail the systematics between ascending and descending orbits. Furthermore, we will analyze the relationship between backscatter, plant structure, plant and soil water content in detail to understand specific structural and seasonal effect, such as the observed seasonality in coniferous forests.

\section{REFERENCES}

Bauer, L., 2013. Vergleichende Hydrogeographie von Thüringen: Ein wasserhistorischer Rückblick. Jena, Suhl: Arbeitsgruppe Artenschutz Thüringen e. V; Verband für Angeln und Naturschutz Thüringen e.V.

Beale, J., Snapir, B., Waine, T., Evans, J., Corstanje, R., 2019. The significance of soil properties to the estimation of soil moisture from C-Band synthetic aperture radar. Hydrology and Earth System Sciences Discussion, doi.org/10.5194/hess-2019-294.

Bossard, M., Feranec, J., Otahel, J., 2000. CORINE land cover technical guide Addendum 2000. Technical report, 40. Copenhagen: European Environment Agency. eea.europa.eu/publications/tech40add. (21.01.2020).

Charbonneau, F., Trudel, M., Fernandes, R., 2005. Use of Dual Polarization and MultiIncidence SAR for soil permeability mapping. Advanced Synthetic Aperture Radar (ASAR) 2005
Cremer, F., Urbazaev, M., Berger, C., Mahecha, M. D., Schmullius, C., \& Thiel, C. 2018 An image transform based on temporal decomposition. IEEE Geoscience and Remote Sensing Letters, 15(4), 537-541.

Dostálová, A., Milenkovic, M., Hollaus, M., Wagner, W., 2016. Influence of Forest Structure on the Sentinel-1 Backscatter Variation-Analysis with Full-Waveform LiDAR Data. Living Planet Symposium, Vol. 740, p. 202.

Dostálová, A., Wagner, W., Milenković, M., Hollaus, M., 2018. Annual seasonality in Sentinel-1 signal for forest mapping and forest type classification. International journal of remote sensing, 39(21), 7738-7760.

Eklundh, L., Jönsson, P., 2016. TIMESAT for processing time series data from satellite sensors for land surface monitoring. Multitemporal Remote Sensing, eds. Y. Ban, Springer International Publishing, pp. 177-194.

Feranec, J., Jaffrain, G., Soukup, T., Hazeu, G., 2010. Determining changes and flows in European landscapes 1990-2000 using CORINE land cover data. Applied geography, 30(1), 19-35.

Gao, Q., Zribi, M., Escorihuela, M., Baghdadi, N., Segui, P., 2018. Irrigation mapping using Sentinel-1 time series at field scale. Remote Sensing, 10(9), 1495.

GEE, 2019: Google Earth Engine Documentation developers.google.com/earthengine/sentinel1 (12.11.2019).

Gillespie, T. J., Brisco, B., Brown, R. J., Sofko, G. J., 1990. Radar detection of a dew event in wheat. Remote sensing of environment, 33(3), 151-156.

Harfenmeister, K., Spengler, D., Weltzien, C., 2019. Analyzing temporal and spatial characteristics of crop parameters using Sentinel-1 backscatter dat $a$. Remote Sensing, 11(13), 1569.

Karlson, M., Gålfalk, M., Crill, P., Bousquet, P., Saunois, M., Bastviken, D., 2019. Delineating northern peatlands using Sentinel-1 time series and terrain indices from local and regional digital elevation models. Remote Sensing of Environment, 231, 111252

Koppel, K., Zalite, K., Voormansik, K., Jagdhuber, T., 2017. Sensitivity of Sentinel-1 backscatter to characteristics of buildings. International Journal of Remote Sensing, 38(22), 6298-6318.

Khabbazan, S., Vermunt, P., Steele-Dunne, S., Ratering Arntz, L., Marinetti, C., van der Valk, D., Iannini, L., Molijn, R., Westerdijk, K., van der Sande, C., 2019. Crop monitoring using Sentinel-1 data: A case study from The Netherlands. Remote Sensing, 11(16), 1887.

Malberg, H., 2007. Meteorologie und Klimatologie: Eine Einführung. Springer-Verlag Berlin Heidelberg.

Riedel, T., Liebeskind, P., Schmullius, C. C., 2002. Seasonal and diurnal changes of polarimetric parameters from crops derived by the Cloude decomposition theorem at Lband. IEEE International Geoscience and Remote Sensing Symposium, Vol. 5, pp. 27142716.

Rodionova, N. V., 2018. 2015-2016 Seasonal Variations of Backscattering from Natural Coverage in the Moscow Region Based on Radar Data from the Sentinel 1A Satellite. Izvestiya, Atmospheric and Oceanic Physics, 54(9), 1272-1281.

Roy, J., Hinckley, T. M., 2013. Ecophysiology of coniferous forests. Academic Press.

Rüetschi, M., Schaepman, M. E., Small, D., 2018. Using multitemporal Sentinel-1 C-band backscatter to monitor phenology and classify deciduous and coniferous forests in northern Switzerland. Remote Sensing, 10(1), 55 .

Stendardi, L., Karlsen, S. R., Niedrist, G., Gerdol, R., Zebisch, M., Rossi, M., \& Notarnicola, C., 2019. Exploiting time series of Sentinel-1 and Sentinel-2 imagery to detect meadow phenology in mountain regions. Remote Sensing, 11(5), 542.

Thiel, C., Cartus, O., Eckardt, R., Richter, C., Thiel, C., Schmullius, C., 2009. Analysis of multi-temporal land observation at C-band. Proceedings of International Geoscience and Remote Sensing Symposium IGARSS, Cape Town, Republic of South Africa, pp. 318-321.

TIMESAT, 2017. A software package to analyse time-series of satellite sensor data, Version 3.3. web.nateko.lu.se/timesat/timesat.asp?cat=6 (21.01.2020)

van Emmerik, T., Steele-Dunne, S. C., Judge, J., van de Giesen, N., 2015. Impact of diurnal variation in vegetation water content on radar backscatter from maize during water stress. IEEE Transactions on Geoscience and Remote Sensing, 53(7), 3855-3869.

Veloso, A., Mermoz, S., Bouvet, A., Le Toan, T., Planells, M., Dejoux, J. F., Ceschia, E., 2017. Understanding the temporal behavior of crops using Sentinel-1 and Sentinel-2-like data for agricultural applications. Remote Sensing of Environment, 199, 415-426.

Vreugdenhil, M., Wagner, W., Bauer-Marschallinger, B., Pfeil, I., Teubner, I., Rüdiger, C., Strauss, P., 2018. Sensitivity of Sentinel-1 backscatter to vegetation dynamics: An Austrian case study. Remote Sensing, 10(9), 1396.

Whelen, T., Siqueira, P., 2018. Time series classification of Sentinel-1 agricultural data over North Dakota. Remote sensing letters, 9(5), 411-420.

Zink, M., Samaniego, L., Kumar, R., Thober, S., Mai, J., Schäfer, D., Marx, A., 2016. The German drought monitor. Environmental Research Letters, 11(7), 074002, www.ufz.de/index.php?en=37937. 